\title{
INTERNSHIP DIVERSITY \& MOBILITY: FIRST EXPERIENCES ON SPANISH UNIVERSITIES ${ }^{1}$
}

\author{
María Isabel Beas-Collado ${ }^{1}$, Teresa Martínez-Fernández ${ }^{2}$, Mercedes Segarra- \\ Ciprés $^{3}$ \\ ${ }^{1}$ Head of Careers Service, Universitat Jaume I (SPAIN) \\ ${ }^{2}$ International Placements Coordinator, Faculty of Law and Economics, Universitat Jaume I \\ (SPAIN) \\ ${ }^{3}$ International tutor, Faculty of Law and Economics, Universitat Jaume I (SPAIN)
}

\begin{abstract}
After 13 years of Jaume I University (UJI) experience on international mobility programmes (Leonardo da Vinci, Erasmus Placements, Socially-oriented internships in impoverished countries), more than 500 university students have benefited from them. The project coordination corresponds to the Careers Services (OIPEP), in consultation with a system of coordinators and tutors. As a result of this coordinated work, the quality of this project has been recognised several times by the Autonomous Organization of European Educational Programmes (AOEEP), bounded up with the Ministry of Education. Furthermore, Jaume I University (UJI) relies on a set of services implied on diversity such as the Support Educational Unity and the Careers Services, both of them linked to Vice-Rector for Students, Employment and Educational Innovation. Especially, the Diversity Attention Programme (DAP, 2015), implemented from the UJl's origination, is a model for the rest of the Spanish universities. As a matter of fact, $\mathrm{UJI}$ is nowadays in charge of coordinating the network of Service of Assistance to Disabled People (SADP). The Assistance Diversity Programme (DAP) pretends to give academic support to this university community which requires a specific educational need (SEN) and its teachers.

Inside this context of international and diversity internships, we set the present paper, submitting a pioneering experience in Spain. Concretely, between the years 2013 and 2014 through Leonardo's programme (People in the Labour Market) we implemented an international internship with a graduated disabled students, sponsored by the AOEEP. The complexity of this international internship implied the creation of an ad-hoc group with professors and professional workers in the required areas for the good development of this task. The results were important, not only for our university, but for future and similar experiences in other universities.
\end{abstract}

Keywords: Mobility Programmes, Diversity, University Experience.

\section{INTRODUCTION}

Jaume I University (UJI) is pioneer in international mobility programmes as it is demonstrated by the high number of students (more than 500) that have been benefited from these experiences since 13 years ago. Moreover, its programmes have been recognized several times by the Autonomous Organization of European Educational Programmes (AOEEP), bounded up with the Ministry of Education. The project coordination corresponds to the Careers Services (OIPEP), in consultation with a system of coordinators and tutors.

Nobody doubts about the idea that international internships constitute an important stage for the student body because, they allow students to put in practice the knowledge they have acquired during their formative process. Additionally, among other aspects, students also experience an improvement in the official language of the country where they are and internationalisation as added values to their academic stage.

UJI is also well known for providing a set of services implied on diversity such as the Support Educational Unity and the Careers Services, both of them linked to Vice-Rector for Students, Employment and Educational Innovation. Specifically, the Diversity Attention Programme [1],

\footnotetext{
${ }^{1}$ This project has been funded with support from the European Commission. 2012-1-ES1-LEO02-48828. This publication [communication] reflects the views only of the author, and the Commission cannot be held responsible for any use which may be made of the information contained therein.
} 
implemented from the UJI's origination, is a model for the rest Spanish universities. As a matter of fact, $\mathrm{UJI}$ is nowadays in charge of coordinating the network of Service of Assistance to Disabled People (SADP). The Assistance Diversity Programme pretends to give academic support to this university community which requires a specific educational need (SEN) and its teachers.

Inside this double context, is where our paper is placed and where international mobility and diversity are unified. These aspects have been merged in an international internship experience carried out by UJI, pioneer in this area in Spain. Concretely, between the years 2013 and 2014 through Leonardo's programme (People in the Labour Market) we implemented an international internship with a graduated disabled student, sponsored by the AOEEP. The complexity of this international internship implied the creation of an ad-hoc group with professors and professional workers in the required areas for the good development of this task. The results were important, not only for our university, but for future and similar experiences in other universities.

Hereafter we will explain the main features of Leonardo's programme, its process and the components which intervene in this international internship programme of Jaume I University, as well as the its main achievements. We will continue with the legal framework statement in relation to the international internships for disabled students. Finally, we will make a case study, exploring the protocol for action carried out by the University with all the agents involved in the process.

\section{LEONARDO PROGRAMME PEOPLE IN THE LABOUR MARKET}

Mobility in Lifelong Learning Programme (LLP) [2], Leonardo (Professional training) for "People in the Labour Market", is addressed to people in the labour market like regular employees, freelancers or people available for employment (even graduated) who make a formative/internship stay in this group are included, likewise, graduated on Higher Level Professional Training and not recent University graduate students. This programme finished on May, 2015.

The operational objectives of the programme are:

Improvement of Europe's people mobility in the initial and continuous professional formation stage both qualitatively and quantitatively, in order to achieve that the enterprises reach 80.000 students per year in the Lifelong Learning Programme (LLP).

Improvement of the cooperation both qualitatively and quantitatively between the centres and the organizations which bring the learning opportunities, enterprises, social interlocutors and other organisms relevant from the whole Europe.

Facilitation of the development of innovative practices in the educational area and the professional training outside the service sector and its transference even among different countries.

Improvement of the transparency and recognition of qualifications and competences, including the ones acquire during the informal teaching.

Promotion of modern foreign language learning.

Support the development of contents, services, pedagogies and innovative and permanent learning practices, and based on Information and Communication Technologies (ICT).

According to what is established in the LLP, for "People in the Labour Market" the length of the internship varies from 2 weeks to 26 weeks.

\subsection{Leonardo programme at Jaume I University}

Mobility programmes are linked to the employability and internationalization policies of UJI. Since their beginning, they are coordinated by the Careers Services (OIPEP), which depends on the Vice-Rector for Students, Employment and Educational Innovation. The main objective of the Careers Service is to promote employability and the professional opportunities of graduates and students throughout various programmes and activities. (External internships, Career guidance, Employment monitoring centre, Training for employment, labour exchange, Exhibitions and Conferences, "Ocuparty"). Part of these programmes has some common points. They are placements in companies with an important educational nature, being a formal experience with clear goals, which can be part of the syllabus or not, limited in time dually-supervised (Host company professional and university teacher/tutor), validation and recognition of learning. 
One of the international internship programmes offered by UJI, directed to university graduates, is called Leonardo da Vinci "International internship for recent graduates in Europe" [3], [4]. It was initiated the course 2002-03, addressed to UJI graduates who obtained their degree during the previous 2 years, with a length of 24 weeks working on European union companies (EU), to the countries of the European Economic Area and applicant countries. A founding distort comes from the EU to the programme LLP, co-financed from UJI and also from the host companies. The last Project was of the years 2013-2015, and it count with the quality certification of "Mobility certification of the projects from 2009 to 2013 ".

The project started 2002 and from its beginning it has been coordinated and managed from the OIPEP, the Careers Service office which is dependent on the Vice-chancellor for Students Employment and Educational Innovation, and which is supported by a convincingly institutional support [3], [4]. For its implementation the Careers Service made use of the internship programme curriculum of UJI, area in which our university is leader in Spain. All these other programmes are coordinated as well by the same office, and this is the main reason why we could transfer the experience of other internship programmes to this one. This international programme is coordinated at the same time of the rest programmes (international internships, national internships, vocational and training programmes, occupational training and labour intermediation).

Through time a global academic supporting structure has been consolidated, which has a previous training system about career guidance and employment, as well as linguistic and cultural issues. Moreover, it is a mixed selection system (public-partner welcome call), which is completed throughout a follow-up and tutoring system in charge of academic teachers. A rigorous procedure of evaluation of $360^{\circ}$ is done by the whole parts implicated, previous, during and after finishing the internship with a deep interview. It is important to highlight the implication of EURES net in the project. The participants' procedure of selection, formation and follow-up has been described widely at [5] [6].

Without any pretensions to be exhaustive, referring to the programme main results we are allowed to indicate in a quantitative level that from 2002 to 2013, 334 graduated students have participated in the programme. The evolution in participation has been an ever increasing number until 2009, where a stagnation in the number of graduates who obtained Leonardo's quality certificate took place, because from 2009 to 2013 there was only project financing for 35 participants (Fig. 1).

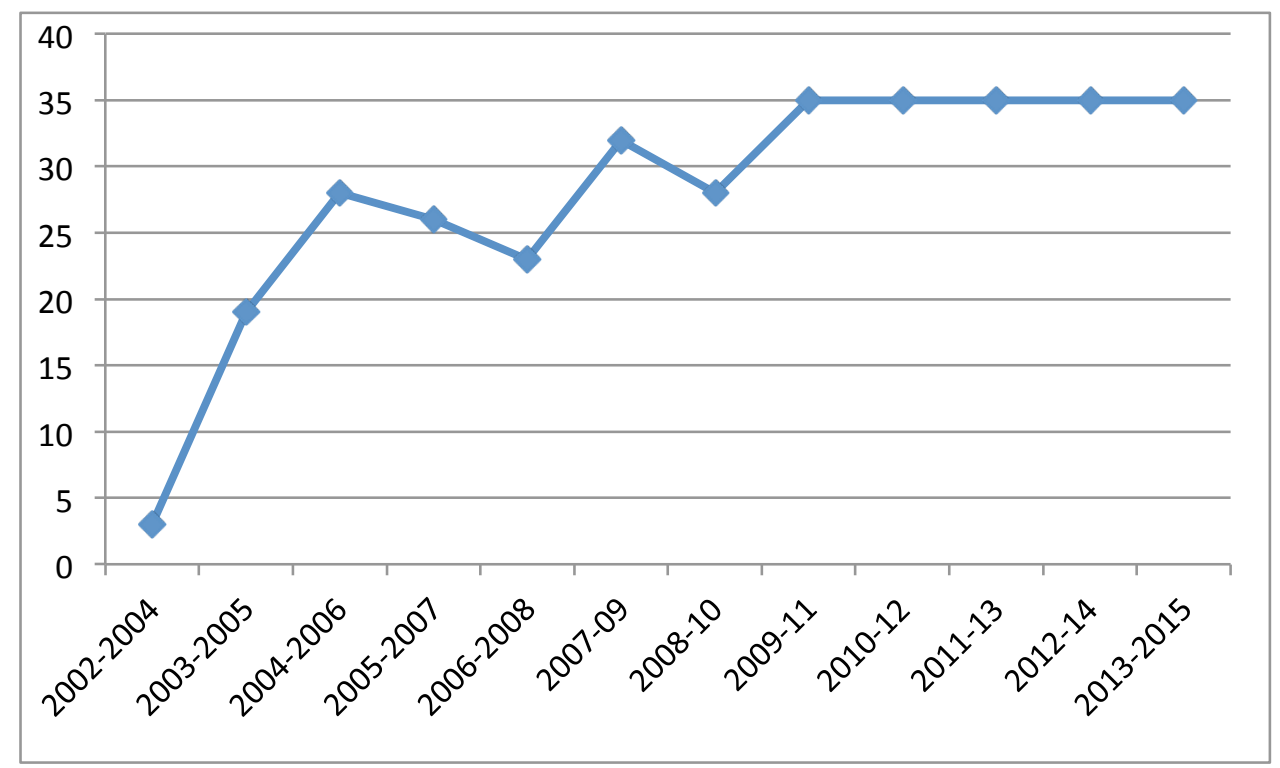

Fig. 1. Participation evolution in Leonardo Programme at UJI. Source: Careers Services.

The participants belong to a 12 different formative profiles (among them it is possible to find Humanity, Law, Administration and Business Management, Industrial engineering or Psychology). They have made their internship in multi-sectoral European companies with the aim of getting a complementary professional training to the university training; development of transversal competences, professionals, linguistics and intercultural concerning their future profession context; helping personal development, active citizenship, social inclusion and insertion of university graduates in the labour market; 
implementing their employability, and increase adjusted employment. One of the objectives of this programme is the achievement of an important impact on employability, understood as the combination of different factors which let individuals progress for getting a job, or remain at the same job and progress along their professional career. [3], [4].

In the empirical studies done previously, [7], [8].we find that international mobility is a significant factor which has impact over the characteristics and situation of current employment, which is compared with those people who have not had this experience: higher adjusted employment for the employed who has an profile trained $(85 \%)$, high responsibility over persons $(30 \%)$ high international insertion $(60 \%)$, higher self-employed rate $(20 \%)$. The results about the mobility participants population comparing their previous situation and 3 months after finishing the mobility show an improvement of professional selfefficiency, an increase in transversal competences, linguistic techniques, the vocational clarification and in some cases the reorientation of the career. In addition, we check out the high level of companies satisfaction, participants and partners' loyalty, for which the internship is an approach to university, an optimal process of talent's retaining and the establishment of mutual trust.

After the self-analysis done and the feedback got from AOEEP, we can conclude that the strong points in the $\mathrm{UJI}$ international internships are: favourable institutional context, professionalization of its management and work-team strengthen, as well as the consolidation of a partner network of host and reliable intermediaries. The work done by UJI has been recognized several times by AOEEP, nomenee to the Quality award in mobility in 2006, awards to various participants in the 2006 and 2007 projects (best experiences) and the Quality Certification 2009. Similarly, UJI has participated in various events, invited by the AOEEP, as speakers and as an example of good internships, for example, in the VI Valuation Fair 2012 [4].

After this wide experience on international internship programmes it is possible to enumerate several conclusions. Career guidance increases effectiveness on graduates when they look for an employment and it is a necessary complement for every training programme. The length of 24 weeks for graduates is appropriate for the established goals. Conversely, training tutors (professors) increase their motivation and commitment. Women are more interested in the programme, and the Englishspeaking destinations are the favourite ones. During last years the concern of participate has rise, being Leonardo Programme the most-known among the whole organized (more than $85 \%$ of students and university graduates) by the Careers Services. [6].

\section{LEGAL FRAMEWORK: SPECIAL PROVISIONS FOR DISABLED PEOPLE}

Leonardo mobility programme 2012 can be consulted in the documents elaborated by AOEEP for the management of the project [9]. It can be underlined some Management Rules for Mobility Beneficiaries, as a summary, it establishes management standards:

1 Elaboration of the Training Agreement for the participant (Signed by the participant, home university, and host company) in which is also included a quality commitment with the contractual obligations of the sender and host entities and the participants.

2 The signature of a grant agreement for the participant (signed between the participant an the home university).

3 A participant certificate of completion, to be signed by the host company.

4 A common set of rules and levels for the calculation of subsides and maintenance tables.

What concerns our case, which is international internship for a person with a high degree of disability, the programme rules defined by the AOEEP are scarce, centred only in minors perspective and thinking on companions who go out Spain.

The definition for disabled people is very limited. The programme talks about "... for projects in which the participants are under 18 or with special necessities (psychically or motor disabled, young people in risk or social exclusion, etc.)." Gives importance to disabled people cases, marking that "for participants with special needs, diet will be incremented to $50 \%$. This additional cost must be requested and approved in the proposal previously, it cannot be requested subsequently."[9]

Another circumstance which is took into account is the possibility of incorporating various companions, always successively, to the participant, as it is indicated in this extract of the programme: "It is accepted that a companion substitutes another workmate during the stay if the circumstances prevent one companion to be during the whole expected stay. In this cases it will be possible claim at the final 
report the travel expenses incurred for each companion, as well as maintenance costs of the invested time in the accompaniment, without exceeding the subside granted in the contract and intended to the companions."

For some questions, that we consider there was no answer from the programme regulations itself, because they were not covered, we made previous queries to AOEEP. Among them, and due to the existence of various companions in this practice, it was confirmed that "For the good financing of this companion by Leonardo's subside, it is necessary that this person accompanies the participant from the beginning to the end."

Another barrier we found was the fact that in the programme it is not well-defined the companions roll, it is only focus in the sound financial accountability, and among other, that the beneficiary (sending organisation) has no right to impute costs, as for example of cultural training, pedagogical and linguistic. Then, some of their answers are transcribed now: 1) "We remember you that the subside for companions it is not destined to finance follow-up visits: these named costs are imputed at the mobility organisation certificate", 2) "It will be not possible to impute organisation, cultural, pedagogic and linguistic training of the companions expenses. It will be not admitted costs derived from companions mobility if they are not advised and approved in the application". 3) "To attach with the final report (or the intermediate report if they will be): evidence from travel expenses and boarding pass where the companion stay date can be checked." In that case, there is no reference to the obligation or necessity to hire an insurance for the companion. Simply, for the justification in front of the AOEEP it is requested to the beneficiary.

Finally, to prove special necessities, evidences from the real incurred costs and documentation related with the need are required.

\section{PRACTICE CASE APPROACH: PROTOCOL FOR ACTION ON INTERNSHIP MOBILITY OF LEONARDO'S DISABLED GRADUATE WITH VARIOUS COMPANIONS}

In our present paper we expose a pioneering experience in Spain on international internships and diversity in high education. The objective is to show a good practice in this context, which main core is protocol for action's definition followed in order to success in a mobility programme as Leonardo by a disabled graduated. Therefore, The last point of this paper will be showing an experience because of the inexistence of a definite protocol, do it in a concrete way for this type of cases, with the aim of being helpful in other cases both in the university area and out of it. To do this, firstly, we will present descriptive data about the internship development context, and secondly, we will made an approach on the organization and planning which was carried out from UJI for offering the participants a quality international internship.

\subsection{Descriptive data from international internship}

The international internship was implemented between 2013 \& 2014 and the participant was a physical disabled graduated (or functional diversity) inside Leonardo's programme from UJI, with additional financing given by AOEEP. Concretely, the beneficiary of this programme was a student of 34 years old, graduated in Business Administration and Management and with a Master on Marketing and Market Research, and suffering a disability superior to $67 \%$. The international internship took place at Naples, Italy, in a local company belonging to the service sector and was carried out in two periods. The first period took place from September to December of 2013 and the second one from January to march of 2014. The internal legal frame was the public call Leonardo 2012 [10].

The workstation for the realization of the international internship required the participant the following knowledge and abilities: a) capacity for analysis and synthesis; b) problem solving; c) information management skills (ability to retrieve and analyse information from different sources); d) oral and written communication in native language; e) elementary computer skills; f) capacity to generate new ideas (creativity); g) initiative and entrepreneurial spirit.

The programme of the training period was divided in 2 phases:

$1^{\text {st }}$. In the first time the participant should study the organization and mission of the company and analyze their business plan and see where it could be improved and propose his tips. In the same time, he could help company in the realization of some market researches. 
$2^{\text {nd }}$. In the second one, the participant was the responsible of data entry of the company and he assisted the responsible of Marketing Department to manage the web communication of the company and operative Marketing campaigns. In parallel, he had to develop a controlling of commercial activities of the company.

\subsection{Internship's organization and planning: delimitation of a protocol for action}

In the organization and planning of the international internship, due to the absence of a previous one to follow, a process of procedure definition was carried out in order to fix the different responsibilities of everybody who intervene in the process. Then, we try to carry an appropriate following of the internship, as well as the establishment of mechanisms for solving quickly and with effectiveness any incidence that could take place. Down below the objectives are detailed, the constituents of the working group ad-hoc formed for the internship management and the barriers and solutions given.

The main objectives of the protocol for actuation which were fixed are the followings:

1 Establish a procedure of companion selection.

2 Assure the company adaptation of participant needs. From this point some features of the workplace and activities to done, adapted to these needs, and collected in a training agreement for the beneficiary.

3 Establish a training agreement adapted to the companion and for specify their tasks and obligations.

4 Establish a procedure for the subside payment for the companion: Include it in the participant subside agreement.

5 Establish a finishing certificate for the companion issued by the participant, collecting the satisfaction with the attention received and dates.

6 Establish an additional continuous follow-up system for the relationship participant-companion.

This international internship complexity involve a workplace ad-hoc creation with professors and professionals in every area which required them for the good-development of this activity. Concretely, a group work was formed by:

1 The institutional coordinator of Leonardo's programme, responsible at the same time of the Careers Services office and counselor.

2 The international internship academic coordinator from the faculty to which the graduate belongs, Faculty of the Legal Sciences and Economy from UJI.

3 The participant's academic tutor and professor from the Business Administration and Marketing Department from UJI.

4 The Diversity Support Unity responsible from UJI.

5 In some cases, the Italian language advisor from Language Service of UJI working as translator.

At last, an international internship as the one we described above and without previous references assume a great challenge both for the participant and for the companion, as for the group work. At the beginning the following barriers appeared:

1 Paucity in the data gathered in the Leonardo's programme norms, especially on the treatment of the companion.

2 Very rigid norms imposed by the AOEEP in disabled people mobility management and their companions.

3 The lack of previous experience in Spain, no referents, about mobility internships in Leonardo programme LMP with companions.

We got solutions thanks to a continuous contact with AOEEP and the reference technician for the Project for clarifying doubts, via telephone or e-mail, and check the eligibility of our proposals on the part of the Ministry of Education, as well as the specific treatment of this case, in a transversal way, from UJI. 


\section{CONCLUSIONS}

International mobility programmes offer developmental professional perspectives for participants, expanding their labour horizons to other countries from the European Union. The interest of the graduates and students in participating in mobility programmes have raised, benefited by their own results but, also due to the economic crisis which makes more real the need of curriculum differentiation and the high impact of have been employed in an international internship.

Since the first moment, UJI have bear in mind among their challenges, to boost the participation of disabled people in each of its programmes encouraging their inclusion and having bigger financings for their mobility. This goal could be achieved at the moment we had a person with a high disability who wished to do an international internship in Leonardo's programme. The challenges were many, because we did not have previous experiences in Spain (according to AOEEP), the time spent too, as well as the great efforts done due to the elevated amount of implicated agents in the experience. The possibility, to give a chance of this type to a participant with functional diversification involves to break down barriers, not just physical barriers, also psychological ones, apart from bureaucratic barriers. This internship has been possible thanks to the participant ability of overcoming their difficulties and the coordinating labour of the group work. The commitment acquired by everybody has derived in a very high levels of satisfaction, for the university, for the company and, of course, for the most important person of this programme, the participant.

\section{REFERENCES}

[1] Diversity Attention Programme at Universitat Jaume I (DAP, 2015)

http://ujiapps.uji.es/serveis/use/base/pad/ [Retrieved 2016/01/07].

[2] Lifelong Learning Programme: Oficial Call 2012: http://ec.europa.eu/education/tools/llp_en.htm\#tab-7 [Retrieved 2015/12/23].

[3] Beas, M.I. (2013). "Experiencia de la Universitat Jaume I". Papeles Europeos n5. In: http://modeproject.eu/publicaciones/revista56/book.swf\#p=192 [Retrieved 2015/12/23].

[4] Beas, M.I. (2013). "Buena práctica de movilidad". Universitat Jaume I. In: http://www.oapee.es/oapee/inicio/servicios/Eventos.html [Retrieved 2013/04/08].

[5] Beas, M.I, González, C., Gual, J. y Martínez, M.T. (2013). "Las prácticas externas internacionales de los estudiantes y titulados de la uji: aprendizajes del proceso y retos de futuro". IV Jornada nacional sobre estudios universitarios. El futuro de los títulos universitarios. Servei de Publicacions i Comunicacions de la Universitat Jaume I, 2013. ISBN 978-84-8021942-6.

[6] Martínez-Fernández, T.; Beas-Collado, M.I.; González-Oñate, C. and Gual-Ortí, J. (2014). 12 años de prácticas internacionales en la UJI: Evolución y progreso hacia el Erasmus + 20142020. XXIV Congreso Nacional de ACEDE. Castellón.

[7] Beas, M.I. y Burriel, J.R. (2012). "Successful job entry into the labour market for senior graduates: variables related to employability within the economic crisis". Proceedings of INTED 2012 Conference, pp. 3107-3115. València: International Association of Technology, Education and Development. Retrieved from

http://www.uji.es/bin/serveis/ocie/acil/prog/obser/2012/vreec12.pdf. [Retrieved 2013/04/08].

[8] Burriel, J.R. y Beas, M.I. (2013). "Impact of International Placements in Employability of Graduates from Universitat Jaume I”. Proceedings of INTED 2013 Conference, pp. 4724-4732. València: International Association of Technology, Education and Development. In http://www.uji.es/bin/serveis/ocie/acil/prog/obser/2013/iiplace.pdf [Retrieved 2013/04/08].

[9] Gestión de proyectos Leonardo 2012: OAPEE http://www.oapee.es/oapee/inicio/pap/leonardoda-vinci/proyectos-de-movilidad/gestion-proyectos/gestion2012.html [Retrieved 2015/12/17].

[10] Public Selection Call Leonardo 2012-13 in UJI. In: http://www.uji.es/serveis/ocie/acil/prog/vinci/1213/ [ Retrieved /2016/01/17]. 